\title{
BMJ Global Health Towards global health security: response to the May 2018 Nipah virus outbreak linked to Pteropus bats in Kerala, India
}

Rajeev Sadanadan, ${ }^{1}$ Govindakarnavar Arunkumar, ${ }^{2}$ Kayla F Laserson, ${ }^{3,4}$ Katherine Hartman Heretik, ${ }^{3}$ Sujeet Singh, ${ }^{5}$ Devendra T Mourya,,${ }^{6,7}$ Raman R Gangakhedkar, ${ }^{7}$ Nivedita Gupta, ${ }^{7}$ Rajeev Sharma, ${ }^{3}$ Meera Dhuria, ${ }^{5}$ Sudhir Kumar Jain, ${ }^{5}$ Stuart Nichol, ${ }^{8}$ Promila Gupta, ${ }^{9}$ Balram Bhargava ${ }^{7}$

To cite: Sadanadan $\mathrm{R}$, Arunkumar G, Laserson KF, et al. Towards global health security: response to the May 2018 Nipah virus outbreak linked to Pteropus bats in Kerala, India. BMJ Glob Health 2018;3:e001086. doi:10.1136/ bmjgh-2018-001086

Handling editor Peter MacGarr Rabinowitz

Received 3 August 2018 Revised 28 September 2018 Accepted 28 September 2018

Check for updates

(C) Author(s) (or their employer(s)) 2018. Re-use permitted under CC BY-NC. No commercial re-use. See rights and permissions. Published by BMJ

For numbered affiliations see end of article.

Correspondence to Dr Kayla F Laserson; klaserson@cdc.gov
THE MAY 2018 NIPAH VIRUS OUTBREAK IN KERALA, INDIA, LINKED TO PTEROPUS BATS

This report summarises the complete outbreak timeline and findings, including the association of infection and Pteropus bats, and makes the link to global health security in India.

\section{INTRODUCTION}

On 17 May 2018, 12 days after his brother died of a febrile illness, a male patient in his mid-20s visited a hospital in Kozhikode, Kerala, with a fever. One day later, he was dead-but not before his doctors at Baby Memorial Hospital and Kerala's additional director of public health noticed the similarity of the patient's symptoms, which were consistent with encephalitis, to those of his brother who had died days before. NiV was identified as the cause of death from the patient's samples sent to the Manipal Centre for Virus Research (MCVR) (a Grade I Virus Research and Diagnostic Laboratory of the Indian Council of Medical Research; ICMR) at Manipal Academy of Higher Education (deemed University) in Manipal, Karnataka, on May 18. Additional investigation by scientists at the ICMR's National Institute of Virology (NIV, Biosafety Level-4) in Pune, Maharashtra, quickly reconfirmed Nipah as the cause of this outbreak only 2 days after MCVR's initial confirmation. Nipah claimed 21 lives out of 23 cases in the Kozhikode and Mallapuram districts of Kerala, with a case fatality rate (CFR) of $88.9 \%$ (deaths/laboratory-confirmed cases, 16/18).

$\mathrm{NiV}$ is a member of the family Paramyxoviridae, genus Henipavirus and was initially isolated and identified during a 1999 outbreak

\section{Summary box}

The Nipah virus outbreak in Kerala, India, claimed 21 lives out of 23 cases, with a case fatality rate of 88.9\% (deaths/laboratory-confirmed cases, 16/18).

- This outbreak highlights the ongoing need for laboratory training, increased diagnostic capacity for Nipah virus and pathogens of high consequence, the need for improved hospital infection control and the importance of rapid detection and response.

of encephalitis among pig farmers and people with close contact with pigs in Malaysia and Singapore. ${ }^{12}$ Its name comes from the village in the Malaysian peninsula where pig farmers became ill. Transmission to humans may occur after direct contact with infected bats, pigs or people, with the latter presumably through droplet transmission of bodily fluids. In humans, the infection typically presents as fever, headache, drowsiness, disorientation and confusion, and can also include respiratory and neurological symptoms. ${ }^{3}$

The May 2018 outbreak was the third known NiV outbreak in India. The previous two outbreaks were in Siliguri, West Bengal, in 2001 (45 deaths/66 cases: CFR 68\%) and in Nadia, West Bengal, in 2007 (five deaths/five cases: CFR 100\%). During both outbreaks, which took place prior to critical wet laboratory training in Nipah diagnostics provided under the Global Health Security Agenda (GHSA), India had comparatively lower laboratory capacity, and confirmation of NiV using retrospective analysis and laboratory confirmation required specimen transport and testing at US Centers for Disease Control and Prevention (US CDC) in Atlanta. 


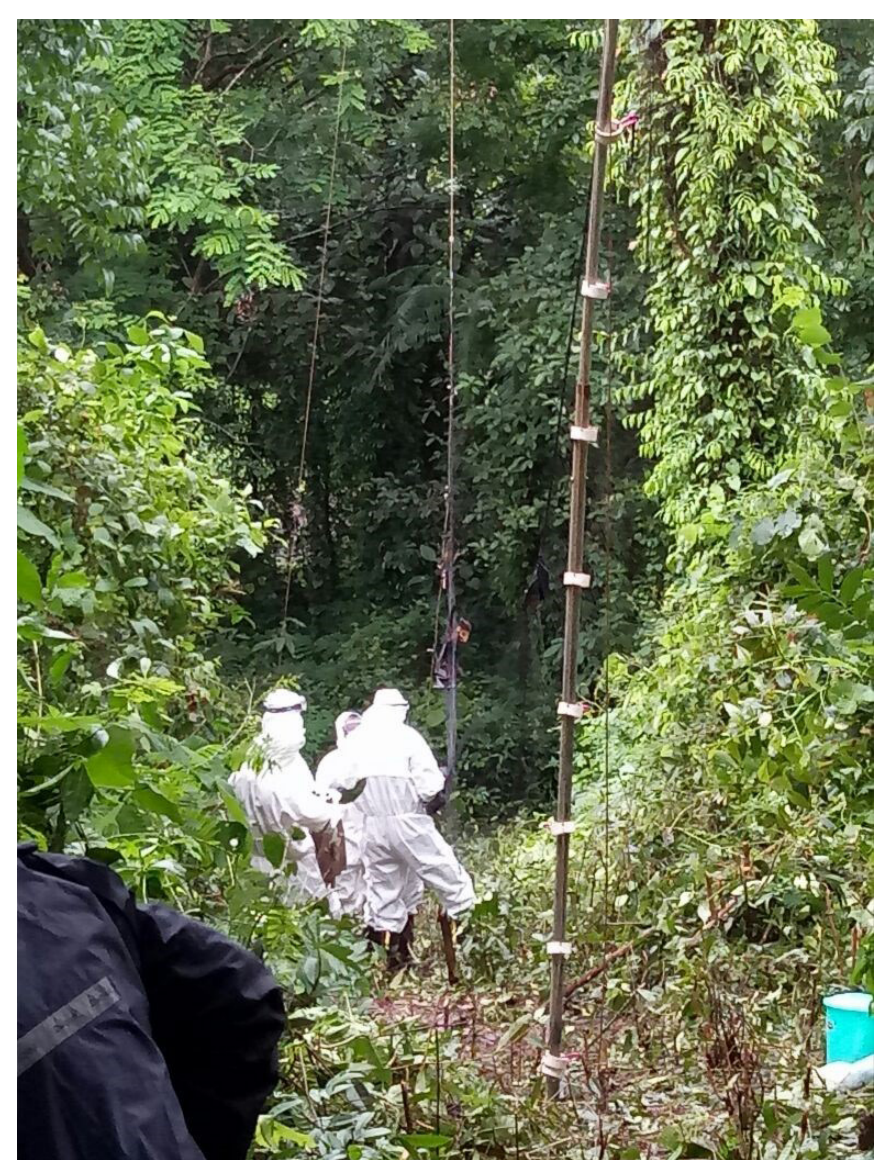

Figure 1 Collecting bats.

In 2018, next-generation sequencing (NGS) analysis implemented under GHSA enabled the MCVR and NIV/ ICMR teams to rapidly sequence the virus's RNA genome and demonstrate that it was similar to the virus previously detected in West Bengal and Bangladesh and dissimilar to the Malaysian or Singaporean strain. This finding allowed doctors to anticipate clinical presentations, including respiratory distress, similar to previous India-based and Bangladesh-based outbreaks. None of the samples were transported to the USA for confirmation.

\section{RAPID, COORDINATED OUTBREAK RESPONSE OF INDIA'S PUBLIC HEALTH SYSTEM}

Kerala's State Surveillance Unit reported the 2018 outbreak to the Central Surveillance Unit of the Integrated Disease Surveillance Programme on May 19; on May 20, NIV reconfirmed NiV. The Government of Kerala's Department of Health and Family Welfare then rapidly initiated public health response measures, including infection prevention and control (IPC), patient isolation and personal protective equipment (PPE) use.

The Union Minister of Health and Family Welfare, Government of India, immediately deployed a multidisciplinary team led by the director of the National Centre for Disease Control (NCDC), including NIV; the All India Institute of Medical Sciences; the Department of Animal Husbandry, Dairying \& Fisheries; the Division

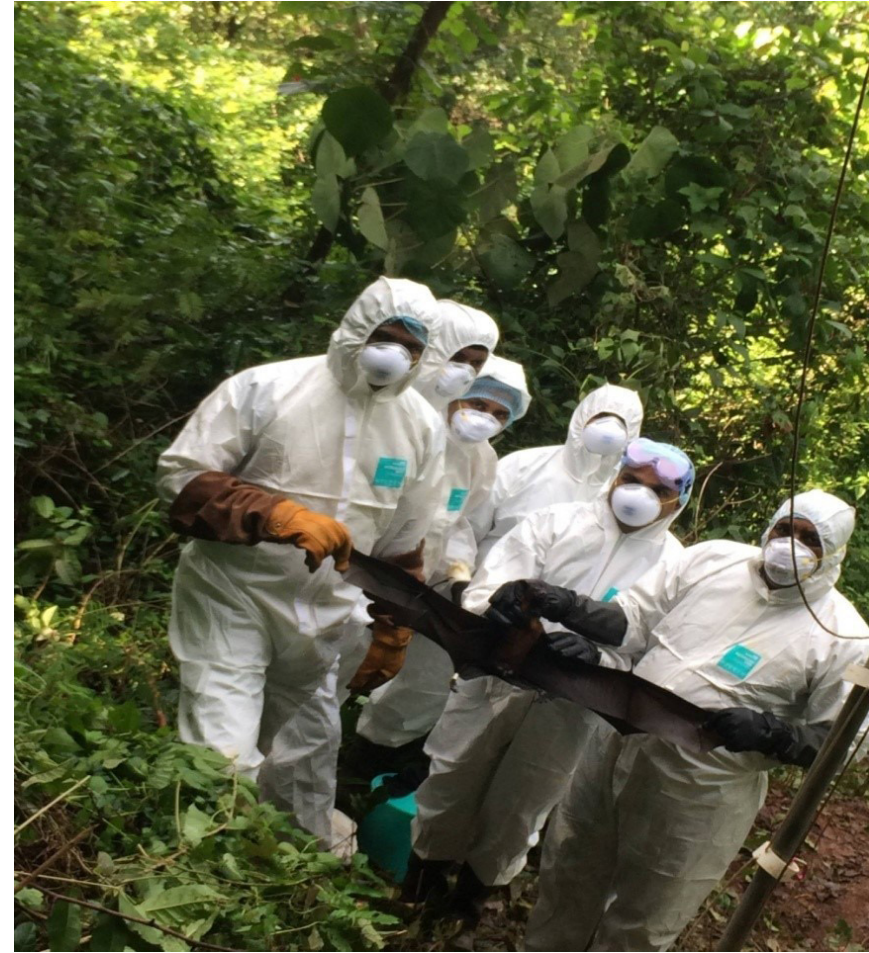

Figure 2 Team with bats.

of Emergency Medical Relief and Ram Manohar Lohia Hospital in New Delhi to provide technical support and work with the Government of Kerala to achieve containment, including active case detection, contact tracing and observation, treatment and management, IPC, safe disposal of human remains, and training and use of PPE by healthcare workers. The Director General of Health Services in the Ministry of Health and Family Welfare also convened the joint monitoring group to review the situation.

Additionally, under the leadership of the Director of the NCDC, the Government of India activated the NCDC Strategic Health Operations Centre (SHOC) to monitor the outbreak and issue daily situation reports, including to the Minister of Health, to support nationwide crisis management.

${ }^{3}$ The Nipah link with the Pteropus bats was confirmed and established by NIV/ICMR, with 19.2\% (10/52) of the bats testing positive (real time real-time reverse transcription polymerase chain reaction (RT-PCR) for detecting NiV RNA; (figures 1 and 2).

In search for the outbreak's source, teams from NIV Pune collected and tested bat samples, given that Pteropus (flying fox) fruit bats had been found to be key disease reservoirs in previous Nipah outbreaks. ${ }^{3}$ The Nipah link with the Pteropus bats was confirmed and established by NIV/ICMR, with $19.2 \%(10 / 52)$ of the bats testing positive (real time real-time reverse transcription polymerase chain reaction (RT-PCR) for detecting NiV RNA; (figures 1 and 2).

Finally, Kerala's state government approached the Queensland Department of Health in Australia to secure limited human monoclonal antibody m102.4 
for treatment and postexposure prophylaxis of additional cases. Kerala also imported ribavirin, an antiviral medication, from Malaysia within days. This outreach was facilitated by ICMR and India's Central Drugs Standard Control Organisation. While there are no licensed vaccines or therapeutics for $\mathrm{NiV}$ apart from intensive supportive measures, such as mechanical ventilation and prevention of secondary infections, the antibody has undergone a phase I clinical trial, and there is evidence of effectiveness in non-human primates. ${ }^{45}$ Ribavirin has been effective in treating other febrile illnesses, although its clinical usefulness in treating $\mathrm{NiV}$ is uncertain. ${ }^{3}$

The state and central teams and all partners' collaborative efforts on timely diagnosis, real-time data sharing, sample transport and contact tracing were key to successfully containing the outbreak.

Efforts to understand local risk factors, including environmental investigations, continue and will contribute both to a better understanding of transmission during this outbreak and to improve prevention and control in the future. Important focus areas for future outbreaks highlighted during the 2018 Kozhikode Nipah response include hospital infection control practices and formalised collaboration between local-level, state-level and national-level public health practitioners and government officials.

\section{GHSA'S IMPACT ON THE 2018 NIPAH OUTBREAK}

MCVR and NIV Pune were both in a unique position to detect and confirm the Nipah diagnosis because of their involvement with the GHSA and collaboration with the US CDC.

Launched in February 2014, GHSA is a growing partnership of over 64 nations, international organisations and non-governmental stakeholders to help build countries' capacity to create a world safe from infectious disease threats and elevate global health security as a national and global priority. It was significantly expanded on the heels of the West African Ebola outbreak in 2014 to make sure that the world would be ready to prevent, detect and espond to future infectious disease outbreaks. ${ }^{6}$

GHSA builds on the WHO International Health Regulations which provide guidance for countries to assess and manage serious health threats that have the potential to spread beyond borders. ${ }^{7}$

In India, GHSA focuses specifically on the 'Core 4' public health functions: increasing real-time surveillance of potential public health threats, strengthening laboratory systems, ensuring more health workers are well trained in key epidemiological capacities and establishing emergency operations centres/SHOCs with rapid response teams capable of activating a coordinated emergency response.

India's GHSA projects are implemented through 17 institutional partners, including NCDC, MCVR, and NIV/ICMR.

Through their partnership under GHSA, the US CDC provided in-country wet laboratory training to participants from MCVR and NIV in August 2017. This training-a part of the ongoing GHSA-funded hospital-based surveillance of acute febrile illness led by MCVR-helped increase diagnostic capacity and gave participants the skills to successfully investigate causes of acute febrile illnesses. In addition, US CDC shared technical expertise, specific reagents and training for diagnosis of dangerous viruses including Nipah and Crimean-Congo haemorrhagic fever through techniques including the NGS analysis technology critical to MCVR and NIV's laboratory confirmations of the NiV in 2018.

Less than 1 year later, scientists at MCVR used those skills, including NGS, to detect $\mathrm{NiV}$ as the pathogen responsible for the 2018 outbreak-for the first time without requiring sample transport outside of India. This early detection, with a turnaround time of only 12 hours, then paved the way for state and central governments to respond to Nipah more quickly than in previous outbreaks, likely limiting the severity of the outbreak and potentially reducing costs in terms of loss of life and commerce (given the role of international fruit and vegetable trade in Kerala farmers' livelihoods). It also may have helped to limit Nipah's spread beyond the geographic area initially affected.

\section{Author affiliations}

${ }^{1}$ Department of Health \& Family Welfare, Government of Kerala, Kerala, India ${ }^{2}$ Manipal Centre for Virus Research, Manipal Academy of Higher Education (Deemed to be University), Manipal, India

${ }^{3}$ Centers for Disease Control and Prevention, India Country Office, New Delhi, India ${ }^{4}$ Division of Global Health Protection, Center for Global Health, CDC Atlanta, Atlanta, Georgia, USA

${ }^{5}$ National Centre for Disease Control, Ministry of Health and Family Welfare, Government of India, Delhi, India

${ }^{6}$ National Institute of Virology, Indian Council of Medical Research, Government of India, Pune, India

${ }^{7}$ Indian Council of Medical Research (ICMR), Government of India, Delhi, India ${ }^{8}$ Viral Special Pathogens Branch, Division of High-Consequence Pathogens and Pathology, National Center for Emerging and Zoonotic Infectious Diseases, CDC Atlanta, Georgia, USA

${ }^{9}$ Ministry of Health and Family Welfare, Government of India, New Delhi, India

Contributors RSa oversaw the outbreak response in Kerala. GA and DTM performed diagnostic testing for the response. KFL and SN assisted India with building diagnostic capacity and the Global Health Security Agenda implementation in India. PG, SS, RSh, SKJ and MD oversaw the central outbreak response and reporting. KHH drafted the first draft of the article. RRG and NG oversaw diagnostics and next-generation sequencing at the Indian Council of Medical Research (ICMR)/ National Institute of Virology. BB directed the ICMR and oversaw the entire ICMR response.

Disclaimer The findings and conclusions in this report are those of the authors and do not necessarily represent the official position of the US Centers for Disease Control and Prevention/the Agency for Toxic Substances and Disease Registry or the Ministry of Health and Family Welfare, Government of India.

Competing interests None declared.

Patient consent Not required.

Ethics approval Manipal University.

Provenance and peer review Not commissioned; externally peer reviewed.

Data sharing statement All preliminary data from this outbreak are available now and final data will be available once the findings have been published.

Open access This is an open access article distributed in accordance with the Creative Commons Attribution Non Commercial (CC BY-NC 4.0) license, which permits others to distribute, remix, adapt, build upon this work non-commercially, and license their derivative works on different terms, provided the original work is 
properly cited, appropriate credit is given, any changes made indicated, and the use is non-commercial. See: http://creativecommons.org/licenses/by-nc/4.0/

\section{REFERENCES}

1. Outbreak of Hendra-like virus--Malaysia and Singapore, 1998-1999. Can Commun Dis Rep 1999:25:108-12.

2. Centers for Disease Control and Prevention (CDC). Update: outbreak of Nipah virus--Malaysia and Singapore, 1999. MMWR Morb Mortal Wkly Rep 1999;48:335-7.

3. U.S. Centers for Disease Control and Prevention. Nipah virus. Available from: https://www.cdc.gov/vhf/nipah/index.html
4. Australia New Zealand Clinical Trials Registry. Trial registered on ANZCTR (2016, 11 29). Available from: https://www.anzctr.org.au/ Trial/Registration/TrialReview. aspx?id=368110

5. Bossart KN, Geisbert TW, Feldmann $\mathrm{H}$, et al. A neutralizing human monoclonal antibody protects african green monkeys from hendra virus challenge. Sci Transl Med 2011;3:ra103.

6. U.S. Centers for Disease Control and Prevention. Global health security agenda: action packages. Available from: https://www.cdc. gov/globalhealth/security/actionpackages/default.htm

7. World Health Organization. International Health Regulations (IHR). Available from: http://www.who.int/topics/international_health regulations/en/ 